\title{
Editorial
}

\section{Wave-Structure Interaction Processes in Coastal Engineering}

\author{
Francesco Aristodemo ${ }^{1, *(D)}$ and Marcello Di Risio ${ }^{2}$ (D) \\ 1 Dipartimento di Ingegneria Civile, Università della Calabria, Via Bucci, Cubo 42B, \\ 87036 Arcavacata di Rende, Italy \\ 2 Dipartimento di Ingegneria Civile, Edile-Architettura, Ambientale, Università di L'Aquila, P.le Pontieri 1, \\ Monteluco di Roio, 67040 L'Aquila, Italy; marcello.dirisio@univaq.it \\ * Correspondence: francesco.aristodemo@unical.it; Tel.: +39-0984-496554
}

Citation: Aristodemo, F.; Di Risio, M. Wave-Structure Interaction Processes in Coastal Engineering. Water 2021, 13, 831. https://doi.org/10.3390/ w13060831

Received: 15 March 2021

Accepted: 16 March 2021

Published: 18 March 2021

Publisher's Note: MDPI stays neutral with regard to jurisdictional claims in published maps and institutional affiliations.

Copyright: (c) 2021 by the authors. Licensee MDPI, Basel, Switzerland. This article is an open access article distributed under the terms and conditions of the Creative Commons Attribution (CC BY) license (https:// creativecommons.org/licenses/by/ $4.0 /)$.
Among one of the most challenging engineering problems, fluid-structure interaction processes are complex phenomena that have received much attention over the years. When a free surface exists, i.e., within the frame of wave-structure interaction, the role of air and of the sea bottom (either fixed or movable) makes the problem a hard to cut Gordian knot. Nevertheless, the current tremendous computational power and the increasing resolution and accuracy of sensors, both at field and laboratory scales, open new and exciting lines of research aimed at providing professionals with practical tools deriving from rigorous studies.

This Special Issue aims to report the state-of-the-art knowledge on the interaction between water waves (regular, irregular, solitary, and tsunami) and structures in fixed and movable beds.

From December 2018 to January 2021, a total of 14 papers were submitted for consideration for publication in the Special Issue. After a rigorous editorial check and peer-review processes, which involved external and independent experts in the field of coastal engineering, four papers were rejected, and 10 papers were accepted, with an acceptance rate of $71.4 \%$. The work of 30 authors from eight countries around the world highlights the interest in the complex (and fascinating) phenomena of wave-structure interactions.

Figure 1 highlights the word cloud of the keywords published in the papers of this Special Issue. From the analysis of the word cloud, it can be observed that "wave" is the predominant keyword, cited in 8 out of 10 papers, followed by "force" ( 6 out of 10), "hydrodynamic" (4 out of 10), and "hydraulic" and "experiment", which are each cited in 3 articles.

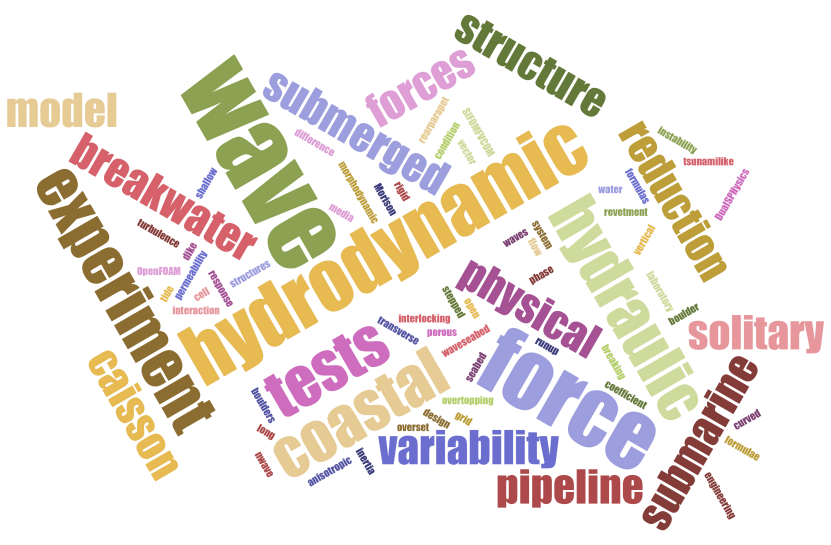

Figure 1. Word cloud of the keywords published in the papers of this Special Issue.

An overview of the contributions of the Special Issue is here carried out.

The first published paper is entitled "Numerical Study of the Influence of Tidal Current on Submarine Pipelines Based on the SIFOM-FVCOM Coupling Model" by Zhao et al. [1]. 
A numerical study on the hydrodynamic forces and the near-flow field induced by tidal currents on submarine pipelines was carried out. A high-fidelity multi-physics modeling system (SIFOM-FVCOM) was adopted for this purpose. After an initial validation, the numerical simulations allowed discovering that the hydrodynamic forces on a bottommounted pipeline increase with the increase of tidal amplitude and the decrease of water depth. In this condition, empirical formulas to evaluate the maximum horizontal and vertical hydrodynamic loads were derived on the basis of the Reynolds and Froude numbers. In scouring conditions below the pipeline, it was observed that the maximum horizontal hydrodynamic forces reduce and the vertical hydrodynamic forces grow with the increase of the scour depth. Regarding the near-flow field, it was observed that the falling vortex behind the pipeline appears flat and long, while the period of vortex shedding is relatively long, and the swirl evolves slowly as well.

The second published paper is entitled "Numerical Study of the Hydrodynamic Characteristics of Submarine Pipelines under the Impact of Real-World Tsunami-Like Waves" by Zhao et al. [2]. In this research, a numerical analysis of the hydrodynamic features of submarine pipelines under the action of tsunami-like waves simulating a wave profile recorded during the 2011 tsunami in Japan was performed. A RANS approach was adopted to perform this investigation. The numerical simulations highlighted that the used tsunamilike waves give larger hydrodynamic forces at submarine pipelines in terms of peaks and duration if compared to the canonical solitary waves. Furthermore, the hydrodynamic forces under tsunami-like waves increase with wave height and pipeline diameter and decrease as the water depth and distance between the pipeline and seabed increase. Analyzing the pipelines in a tandem arrangement, the maximum horizontal (vertical) forces decreased (increased) continuously at both pipelines with increasing spacing distance.

The third published paper is entitled "Beach Morphodynamic Response to a Submerged Reef" by Duarte Nemes et al. [3]. This study paid attention to the morphodynamic response in the lee side of a natural submerged reef placed at an intermediary beach of Rio de Janeiro (Brazil). The field investigation was characterized by a series of surveys of the beach profiles and measurements of the hydrodynamic field, i.e., waves, tides, and currents. The wave breaking vector system on the rocky bank's geometry of the submerged reef was investigated in order to determine the establishment, deformation, and erosion features in the lee of the structure. On the basis of the field results, it was found that the wave-breaking vector system on the geometry of the submerged structure determines the efficiency for beach protections, hazards, and surfing conditions. Depositional features in the lee of the submerged structure appeared with homogeneous wave breaking vectors over the submerged structure's left arms to reach the beach at the adjacent zones of the structure. Erosion features were established when the wave rays entered obliquely onto the submerged structure and rotated the wave breaking vector system until one of the vectors reached the lee of the structure.

The fourth published paper is entitled "Wave Overtopping of Stepped Revetments" by Kerpes et al. [4]. In this paper, a laboratory campaign was performed to investigate the wave overtopping of stepped revetments having various shapes. The experimental tests were conducted using irregular waves, gentle and steep slopes, breaking and non-breaking conditions, and a wide range of dimensionless freeboard heights. The results obtained by the experimental tests highlighted a strong reduction of wave overtopping induced by stepped revetments in comparison with the smooth ones. Furthermore, it was found that the effectiveness of the overtopping reduction decreased with increasing Iribarren number. The processes governing the energy dissipation of a stepped revetment in relation to the step ratio were analyzed. New empirical formulas for the determination of the roughness coefficient as a function of the step ratio and the wave overtopping at stepped revetments were derived.

The fifth published paper is entitled "Influence of Convex and Concave Curvatures in a Coastal Dike Line on Wave Run-Up" by Subramaniam et al. [5]. The aim of this study was to find the effects of the dike curvature, both convex and concave, on wave 
run-up for regular wave attacks by using Lagrangian and Eulerian numerical models, i.e., DualSPHysics and OpenFOAM, for various dike opening angles. The numerical results were compared with physical model tests performed in a wave basin. A new influence factor was introduced to determine the influence of curvature along the coastal dike line. A mild increase in wave run-up at the center of curvature on a curved dike was noticed in most of the test cases under perpendicular or oblique wave attack. For perpendicular wave attack, clear trends were observed for different opening angles. For inclined wave attack, the influence of the curvature decreases and the run-up for curvatures scatters in the range of straight slopes.

The sixth published paper is entitled "Numerical Investigations of the Instability of Boulders Impacted by Experimental Coastal Flows" by Wang et al. [6]. In this work, the instability of boulders under the impact of tsunami bores, i.e., generated by a quick opening of a water tank, was investigated through a shallow water numerical model. The adopted model was validated against previous laboratory tests performed by the same research group. The main findings of the research revealed that the coastal boulders can start moving when the flow height and flow velocity are lower than the theoretical threshold computed by hydraulic formulas. Furthermore, the destabilization of boulders can be explained by the relevant role of temporary fluctuations of the flow velocity, which are able to move the representative point of the flow in the phase space of the system upward, from the block stability into the block instability region.

The seventh published paper is entitled "Three-Dimensional Wave-Induced Dynamic Response in an Anisotropic Poroelastic Seabed" by Hsu and Hung [7]. The objective of this research was the development of an analytical solution to study three-dimensional waveinduced seabed responses for anisotropic permeability. The proposed analytical solution was based on the assumption of the poroelastic and the partial dynamic soil behavior approximation. This solution considered the inertial force of the soil skeleton for a rapid soil behavior and for predicting three-dimensional dynamic responses comprising the pore pressure and stresses for anisotropic permeability. After a preliminary validation of the solution with literature models, the obtained results showed that a shorter wave period had a greater reduction of pore pressure and an increment of vertical and horizontal effective stresses. Moreover, the amplitude profiles of pore pressure for transverse isotropy and isotropy attenuated more slowly with depth as compared to anisotropic permeability. The amplitude profile of the vertical effective stress for anisotropic permeability was greater than that of transverse isotropy and isotropy, as well as the amplitude profiles of the horizontal effective stresses for isotropic and transverse isotropic permeabilities varied significantly as compared to those for anisotropic permeability.

The eighth published paper is entitled "Evaluation of the Hydraulic Performance of a Rear-Parapet Vertical Breakwater under Regular Waves through Hydraulic Experiments" by Lee and Park [8]. This work focused its attention on the hydraulic performance of a vertical breakwater having parapets placed on the seaside, the harbourside, and at the center of the breakwater. For this purpose, laboratory experiments were performed using regular waves. It was found that the use of a rear parapet proved to be the best solution, reducing the maximum horizontal load on the breakwater by up to about $20 \%$. Furthermore, a mitigation of the impulsive wave pressure can be achieved by increasing the height of the offshore freeboard. Another important finding was related to the significant reduction of the required self-weight and maximum bearing pressure using the rear parapet if compared to a conventional vertical breakwater.

The ninth published paper is entitled "Wave Force Characteristics and Stability of Detached Breakwaters Consisting of Open Cell Caissons Interlocked via Crushed Stones" by Lee et al. [9]. In this paper, the wave force characteristics and stability of a detached breakwater consisting of open cell caissons interlocked via crushed stones were analyzed. In this context, laboratory tests were undertaken in a wave basin, and a series of regular wave attacks was adopted. The experimental forces on the structure were compared with an analytical solution deduced from diffraction theory. The obtained results revealed that 
the wave force acting on the open cell caisson breakwater decreased as the relative length of the breakwater and incident wave angle increased. In addition, the open cell caisson breakwater was more stable than the conventional one for oblique and normal incident waves. To prevent excessive deformations of open cell caissons before the sliding failure, the control of the compaction of the crushed stones or the use of low-flow mortar was finally suggested to reduce the voids.

The tenth published paper is entitled "Determination of Force Coefficients for a Submerged Rigid Breakwater under the Action of Solitary Waves" by Aristodemo et al. [10]. In this work, a laboratory investigation in a wave flume was carried out to calibrate semiempirical models, i.e., Morison and transverse, in order to evaluate the horizontal and vertical hydrodynamic forces induced by solitary waves on a submerged rigid breakwater. Laboratory tests were performed using a rigid square barrier equipped with a battery of pressure sensors to deduce the wave loads and two wave gauges to deduce the surface elevation and the kinematic field. The flow regime of the tests was characterized by the dominance of the inertia force components in the wave direction and of the lift force components in the transversal one, observing that the horizontal loads were generally higher than the vertical ones. The force coefficients (drag, horizontal inertia, lift, and vertical inertia) in the Morison and transverse semi-empirical models were determined using a weighted least squares method on the basis of the time variation of the experimental hydrodynamic forces and the free stream kinematics. The practical purpose of this article was the introduction of empirical equations to determine the force coefficients as a function of the wave non-linearity.

Funding: This research received no external funding.

Acknowledgments: The Guest Editors thank all the authors, Water's Editors, and the reviewers for their great contribution and commitment to this Special Issue.

Conflicts of Interest: The authors declare no conflict of interest.

\section{References}

1. Zhao, E.; Mu, L.; Shi, B. Numerical Study of the Influence of Tidal Current on Submarine Pipeline Based on the SIFOM-FVCOM Coupling Model. Water 2018, 10, 1814. [CrossRef]

2. Zhao, E.; Qu, K.; Mu, L.; Kraatz, S.; Shi, B. Numerical Study on the Hydrodynamic Characteristics of Submarine Pipelines under the Impact of Real-World Tsunami-Like Waves. Water 2019, 11, 221. [CrossRef]

3. Duarte Nemes, D.; Criado-Sudau, F.F.; Gallo, M.N. Beach Morphodynamic Response to a Submerged Reef. Water 2019, 11, 340. [CrossRef]

4. Kerpes, N.B.; Schoonees, T.; Schlurmann, T. Wave Overtopping of Stepped Revetments. Water 2019, 11, 1035. [CrossRef]

5. Subramaniam, S.P.; Scheres, B.; Schilling, M.; Liebisch, S.; Kerpen, N.B.; Schlurmann, T.; Altomare, C.; Schüttrumpf, H. Influence of Convex and Concave Curvatures in a Coastal Dike Line on Wave Run-up. Water 2019, 11, 1333. [CrossRef]

6. Wang, L.; Bressan, L.; Tinti, S. Numerical Investigations on the Instability of Boulders Impacted by Experimental Coastal Flows. Water 2019, 11, 1557. [CrossRef]

7. Hsu, C.-J.; Hung, C. Three-Dimensional Wave-Induced Dynamic Response in Anisotropic Poroelastic Seabed. Water 2020, 12, 1465. [CrossRef]

8. Lee, B.W.; Park, W.-S. Evaluation of the Hydraulic Performance of a Rear-Parapet Vertical Breakwater under Regular Waves through Hydraulic Experiments. Water 2020, 12, 1035. [CrossRef]

9. Lee, B.W.; Jung, J.-S.; Park, W.-S.; Yoon, J.-S. Wave Force Characteristics and Stability of Detached Breakwaters Consisting of Open Cell Caissons Interlocked via Crushed Stones. Water 2020, 12, 2873. [CrossRef]

10. Aristodemo, F.; Tripepi, G.; Gurnari, L.; Filianoti, P. Determination of Force Coefficients for a Submerged Rigid Breakwater under the Action of Solitary Waves. Water 2021, 13, 315. [CrossRef] 